\title{
Vitamin D status, postural sway, and the incidence of falls in elderly community-dwelling Japanese women
}

\author{
Kazutoshi Nakamura • Rieko Oshiki • \\ Koki Hatakeyama • Tomoko Nishiwaki • Kimiko Ueno • \\ Mitsue Nashimoto • Toshiko Saito • Yasuo Tsuchiya • \\ Yoko Okuda $\cdot$ Masaharu Yamamoto
}

Received: 26 April 2006 / Accepted: 13 June 2006/ Published online: 10 August 2006

(C) International Osteoporosis Foundation and National Osteoporosis Foundation 2006

\begin{abstract}
Introduction There is little evidence of a preventive effect of vitamin D on falling in Japanese populations. The purpose of this study was to evaluate the effect of vitamin D status on postural sway, muscle strength, and the incidence of falls in elderly community-dwelling Japanese women. This study utilized a cross-sectional design for
\end{abstract}

\footnotetext{
K. Nakamura $(\bowtie) \cdot$ K. Hatakeyama $\cdot$ Y. Tsuchiya $\cdot$ Y. Okuda $\cdot$

M. Yamamoto

Department of Community Preventive Medicine,

Niigata University Graduate School of Medical

and Dental Sciences,

1-757 Asahimachi-dori,

Niigata 951-8510, Japan

e-mail: kazun@med.niigata-u.ac.jp

R. Oshiki

Department of Physical Therapy,

Niigata University of Health and Welfare,

1398 Shimami-cho,

Niigata 951-3198, Japan

T. Nishiwaki $\cdot K$. Ueno

Department of Nursing, School of Health Sciences,

Niigata University,

2-746, Asahimachi-dori,

Niigata 951-8518, Japan

M. Nashimoto

Nagaoka Nursing School,

Kamitomioka-cho 1961-21,

Nagaoka 940-2135, Japan

T. Saito

Department of Health and Nutrition,

Niigata University of Health and Welfare,

1398 Shimami-cho,

Niigata 951-3198, Japan
}

postural sway and muscle strength as outcomes and a prospective design for the 1-year incidence of falls.

Methods Subjects included 633 ambulant elderly women 69 years of age and older who participated in the baseline examinations of the Muramatsu Study. Measurements of serum 25-hydroxyvitamin $\mathrm{D}(25[\mathrm{OH}] \mathrm{D})$ and 1,25-dihydroxyvitamin $\mathrm{D}\left(1,25[\mathrm{OH}]_{2} \mathrm{D}\right)$ concentrations, intact parathyroid hormone $(\mathrm{PTH})$, locus length $(\mathrm{cm} / \mathrm{s})$ of gravity-center sway, grip strength, body height, body weight, body mass index (BMI), and physical activity levels were recorded. Falls that occurred between May 2003 and early July 2004 were documented.

Results The average age and serum 25(OH)D concentration of the subjects was 74.3 years (SD 4.4) and $60.0 \mathrm{nmol} / \mathrm{l}$ (SD 17.9), respectively. The 1-year cumulative incidence of falls was $73 / 609(12.0 \%)$. Multiple linear regression analysis showed that log-transformed locus length of the center of gravity was associated with age $\left(\mathrm{R}^{2}=0.069, P<0.0001\right)$ and BMI $\left(\mathrm{R}^{2}=0.025, P<0.0001\right)$ and that grip strength was associated with age $\left(\mathrm{R}^{2}=0.141, P<0.0001\right)$ and height $\left(\mathrm{R}^{2}=0.100, P<0.0001\right)$. A subgroup analysis revealed that log-transformed locus length was significantly associated with serum $25(\mathrm{OH}) \mathrm{D}$ concentrations $\left(\mathrm{R}^{2}=0.075, P=0.0189\right)$ in 75 subjects who had vitamin $\mathrm{D}$ insufficiency [serum 25 $(\mathrm{OH}) \mathrm{D}<40 \mathrm{nmol} / \mathrm{l}]$.

Conclusions The 1-year incidence of falls was associated with locus length of gravity-center sway. The present study failed to find associations between vitamin D status and gravity-center sway, grip strength, or the incidence of falls. This may be due to relatively high serum 25(OH)D level differences in this population. However, a significant association between vitamin D status and postural sway was found in the vitamin-D-insufficient subgroup, suggesting supplementation of vitamin D should be considered for those with vitamin D insufficiency. 
Keywords Elderly $\cdot$ Cohort studies $\cdot$ Falls . Musculoskeletal equilibrium · Vitamin D

\section{Introduction}

Recent reviews have revealed that vitamin D deficiency impairs muscle function and increases risk of falls $[1,2]$. Vitamin D receptors exist in muscle tissues [3, 4], which explains the molecular mechanisms of vitamin $\mathrm{D}$ action on muscle function. Low levels of vitamin D are reported to be associated with impaired muscle strength, decreased psychomotor function, and increased body sway [5-7]. Furthermore, supplementation of vitamin D has been reported to reduce body sway and number of falls in the elderly [8-10]. These findings suggest that vitamin D has the potential to prevent osteoporotic fractures that result from falls. Significant associations between vitamin D status and fall-related parameters have been observed in inactive elderly people with poor vitamin D status. Recent reports show, however, that such associations are also found in active elderly populations with better vitamin D status [11, 12]. The extant literature thus suggests that vitamin D may be effective in preventing falls in general elderly populations.

Previous studies have been conducted exclusively among Caucasian populations. In fact, no studies to date have been conducted with an Asian population. Some evidence suggests that elderly Japanese populations experience a lower occurrence of falls than Caucasian populations [13]. Recently, however, the incidence of osteoporotic fractures in Japan is steeply increasing [14]. In this context, it remains uncertain whether vitamin $\mathrm{D}$ has a preventive effect against falling in Japanese populations. The purpose of this study was to evaluate the effect of vitamin D status on postural sway, muscle strength, and the incidence of falls in elderly community-dwelling Japanese women.

\section{Subjects and methods}

\section{Subjects}

Subjects included 775 ambulant female volunteers 69 years of age and older who participated in baseline examinations of the Muramatsu Study, an epidemiologic study on osteoporotic fractures conducted between May and early July 2003. Letters were mailed to all households in the town of Muramatsu (female population $\geq 70$ years old: 2,658 ) that invited all women 70 years of age or older as of 31 March 312004 to participate in the study [15]. The participation rate was $655 / 1,497(43.8 \%)$ of women in their $70 \mathrm{~s}, 117 / 920(12.7 \%)$ of women in their $80 \mathrm{~s}$, and $3 / 241$
$(1.2 \%)$ of women in their $90 \mathrm{~s}$ and older. Of the 775 participants, 19 women taking a minor tranquilizer and 123 women taking an alfacalcidol were excluded because of the potential effect on sense of balance. Consequently, 633 subjects were analyzed. Written informed consent was received from all subjects. This study was approved by the Ethics Committee of Niigata University School of Medicine.

\section{Blood examinations}

Vitamin D levels were assessed by measuring serum 25hydroxyvitamin D (25[OH]D) and 1,25-dihydroxyvitamin D $\left(1,25[\mathrm{OH}]_{2} \mathrm{D}\right)$ concentrations. Nonfasting blood specimens were drawn and stored at $4^{\circ} \mathrm{C}$. Serum was obtained from the blood specimens within $12 \mathrm{~h}$ and immediately preserved at $-20^{\circ} \mathrm{C}$ until biochemical analysis. Serum 25 $(\mathrm{OH}) \mathrm{D}$ concentrations were determined by the Nichols Advantage chemiluminescent assay (Nichols Institute Diagnostics, San Clemente, CA, USA) with an interassay CV value of $2.4 \%$. Serum $1,25(\mathrm{OH})_{2} \mathrm{D}$ concentrations were determined by radioimmunoassay (IDS Ltd., Boldon, England, UK), with an interassay $\mathrm{CV}$ value of $6.0 \%$. Serum intact parathyroid hormone (intact PTH) concentrations were measured to evaluate secondary hyperparathyroidism due to vitamin D insufficiency. Intact PTH concentrations were determined with a two-site immunoradiometric assay (Nichols Institute Diagnostics, San Clemente, CA, USA), with an interassay $\mathrm{CV}$ value of $8.4 \%$.

\section{Physical examinations}

Postural sway was evaluated by measuring gravity-center sway. Subjects stood in the standard Romberg position [16] on a gravicorder (GS-10, Anima, Inc., Tokyo, Japan) [17]. Subjects stood for $30 \mathrm{~s}$ looking at a round mark $(3 \mathrm{~cm}$ in diameter) placed $2 \mathrm{~m}$ in front of their eyes. Researchers ensured that the subjects looked at the mark during all measurements. The locus length (per second) of gravitycenter sway was recorded. Grip strength was measured with a digital hand dynamometer (T.K.K.5401, Takei Scientific Instruments Co., Ltd., Niigata, Japan) once each for the right and left hands. The average value of both hands was recorded as the grip strength. Body height and weight were measured to the nearest $1 \mathrm{~mm}$ and $100 \mathrm{~g}$, respectively, while the subjects wore only light underclothes, and body mass index (BMI) was calculated by weight $(\mathrm{kg}$ ) divided by the square of height $(\mathrm{m})$.

\section{Other measurements}

Demographic and lifestyle characteristics, disease history, and current medication were obtained through subject 
interviews. Physical activity levels were assessed based on whether subjects regularly engaged in the following activities: (1) housework; (2) light exercise (such as gate ball or croquet), taking walks, traditional Japanese dancing; and (3) farm work, coded as 0 for "no" and 1 for "yes". Calcium intake was estimated by a semiquantitative food frequency questionnaire [15].

Cumulative incidence of falls (1-year follow-up)

A fall was defined as "an event that results in a person coming to rest inadvertently on the ground or other lower level" [18]. Falls due to an intrinsic cause, such as syncope, or a clear extrinsic cause, such as a motor vehicle accident, were excluded from this study. The authors confirmed falls that occurred in the 1-year time period by one of two ways. Five hundred and twenty-seven subjects were reinterviewed when they participated in an annual health check-up program provided by the Muramatsu Town between May and early July 2004. Researchers also mailed or made telephone calls to the other 223 subjects who could not be interviewed and asked whether they had falls in the followup period. Ultimately, 609 (96.2\%) subjects were questioned. A subject who fell at least once was coded as 1 and who did not was coded as 0 .

\section{Statistical analysis}

Means and standard deviations were calculated for each variable. Because variables of serum $1,25(\mathrm{OH})_{2} \mathrm{D}$ concentration, serum intact PTH concentration, and locus length of gravity-center sway were skewed to higher values, they were transformed logarithmically for the statistical tests. Simple linear regression analysis was conducted to evaluate linear associations between a continuous outcome variable (log-transformed locus length of gravity-center sway or grip strength) and other variables as predictors. The stepwise method of multiple linear regression analysis was used to determine independent variables predicting the continuous outcome variables. The relative risk for one or more falls compared with no falls was calculated for each variable. The PC-SAS (release 8.02, SAS Institute Inc., Cary, NC, USA) was used for computation. A $P$ value less than 0.05 was judged to be statistically significant.

\section{Results}

Baseline characteristics of the subjects are shown in Table 1. Physical activity levels varied. Five hundred and sixty-three (89.1\%) subjects did housework and 69 (10.9\%) did not; $214(33.9 \%)$ participated in light activity and 417 (66.1\%) did not; and 325 (51.4\%) engaged in farm work and 307
(48.6\%) did not. The 1-year cumulative incidence of falls was $73 / 609(12.0 \%)$.

Simple and multiple regression analyses were conducted to explore factors associated with locus length of gravitycenter sway. Simple linear regression analysis showed that log-transformed locus length was associated positively with age $\left(\beta=0.0226, \mathrm{R}^{2}=0.069, P<0.0001\right)$ and negatively with weight $\left(\beta=-0.00884, \mathrm{R}^{2}=0.034, P<0.0001\right)$ and BMI $(\beta=$ $\left.-0.0205, \mathrm{R}^{2}=0.033, P<0.0001\right)$ but not with serum $25(\mathrm{OH})$ $\mathrm{D}(P=0.3410), \log$-transformed $1,25(\mathrm{OH})_{2} \mathrm{D}(\mathrm{P}=0.2807)$, or log-transformed intact PTH $(P=0.5051)$ concentrations. In the same manner, simple linear regression analysis showed that grip strength was associated positively with height ( $\left.\beta=0.326, \mathrm{R}^{2}=0.169, P<0.0001\right)$, weight $(\beta=0.144$, $\left.\mathrm{R}^{2}=0.064, P<0.0001\right)$, and "doing housework" $(\beta=1.83$, $\left.\mathrm{R}^{2}=0.017, P=0.0013\right)$ and negatively with age $(\beta=-0.382$, $\left.P<0.0001, \mathrm{R}^{2}=0.141\right)$ but not with serum $25(\mathrm{OH}) \mathrm{D}$ $(P=0.5712), \log$-transformed $1,25(\mathrm{OH})_{2} \mathrm{D}(P=0.2439)$, or log-transformed intact PTH $(P=0.6480)$ concentrations. Results of stepwise multiple logistic regression analyses are shown in Table 2. Multiple linear regression analysis showed that log-transformed locus length was associated independently with age and BMI and that grip strength was associated independently with age and height.

Similar analyses were conducted with a subgroup of 75 subjects who had serum levels of $25(\mathrm{OH}) \mathrm{D}<40 \mathrm{nmol} / \mathrm{l}$. This serum level is the threshold value of $25(\mathrm{OH}) \mathrm{D}$ at which PTH begins to rise in this population [19]; therefore, the 75 subjects were considered to have vitamin D insufficiency. In this subgroup, log-transformed locus length was significantly associated with serum $25(\mathrm{OH}) \mathrm{D}$ concentrations $\left(\beta=-0.0190, \mathrm{R}^{2}=0.075, P=0.0189\right.$ ) (Fig. 1) but was not associated with other variables. Grip strength was not associated with serum $25(\mathrm{OH}) \mathrm{D}$ concentrations $(P=0.4576)$.

Table 1 Baseline characteristics of the 633 subjects

\begin{tabular}{lll}
\hline & Mean & SD \\
\hline Age (years) & 74.3 & 4.4 \\
Height $(\mathrm{cm})$ & 146.0 & 5.6 \\
Weight $(\mathrm{kg})$ & 49.5 & 7.8 \\
Body mass index $\left(\mathrm{kg} / \mathrm{m}^{2}\right)$ & 23.2 & 3.3 \\
Locus length $^{\mathrm{a}}(\mathrm{cm} / \mathrm{sec})$ & 2.1 & 0.9 \\
Grip strength $^{\mathrm{b}}(\mathrm{kg})$ & 20.1 & 4.4 \\
Calcium intake $(\mathrm{mg} / \mathrm{day})$ & 581 & 249 \\
Serum 25-hydroxyvitamin $\mathrm{D}^{\mathrm{c}}(\mathrm{nmol} / \mathrm{l})$ & 60.0 & 17.9 \\
Serum 1,25-dihydroxyvitamin D $(\mathrm{pmol} / \mathrm{l})$ & 144.4 & 47.0 \\
Serum intact parathyroid hormone ${ }^{\mathrm{c}}(\mathrm{pmol} / \mathrm{l})$ & 3.8 & 1.8 \\
Serum albumin $(\mathrm{g} / \mathrm{dl})$ & 4.2 & 0.2 \\
\hline${ }^{a}$ Three values missing & & \\
${ }^{b}$ Eight values missing & & \\
${ }^{c}$ One value missing & &
\end{tabular}


Table 2 Results of the stepwise method of multiple linear regression analysis

\begin{tabular}{|c|c|c|c|c|c|}
\hline Outcome variable & Independent variable & Regression coefficient & Standard error & $\mathrm{R}^{2}$ & $P$ value \\
\hline \multirow[t]{2}{*}{ Log-transformed locus length $(\mathrm{cm})$} & Age & 0.0214 & 0.0033 & 0.069 & $<0.0001$ \\
\hline & Body mass index & -0.0180 & 0.0043 & 0.025 & $<0.0001$ \\
\hline \multirow[t]{2}{*}{ Grip strength (kg) } & Age & -0.286 & 0.037 & 0.141 & $<0.0001$ \\
\hline & Height & 0.261 & 0.029 & 0.100 & $<0.0001$ \\
\hline
\end{tabular}

Relative risks for falls according to levels of possible risk factors are shown in Table 3. The third quartile $(\geq 145.8,<149.8 \mathrm{~cm})$ of height had significantly higher risk than the fourth quartile (reference). The second $(\geq 1.5$, $<1.9 \mathrm{~cm} / \mathrm{s})$ and fourth quartiles $(\geq 2.5 \mathrm{~cm} / \mathrm{s})$ of locus length of gravity-center sway had significantly higher risk than the first quartile $(<1.5 \mathrm{~cm} / \mathrm{s})$. No other variable had a statistically significant relative risk.

\section{Discussion}

The present study failed to demonstrate an association between vitamin $\mathrm{D}$ status and postural sway, muscle strength, or the 1-year incidence of falls in ambulant elderly Japanese women. This result is inconsistent with a number of studies that showed an association between vitamin $\mathrm{D}$ and balance as well as incidence of falls in the elderly. A previous metaanalysis demonstrated that vitamin D supplementation reduces risk of falls in the elderly by more than 20\% [9]. Also, a large cross-sectional study recently showed that $25(\mathrm{OH}) \mathrm{D}$ concentrations between 40 and $94 \mathrm{nmol} / 1$ were associated with better musculoskeletal function in the lower extremities than concentrations

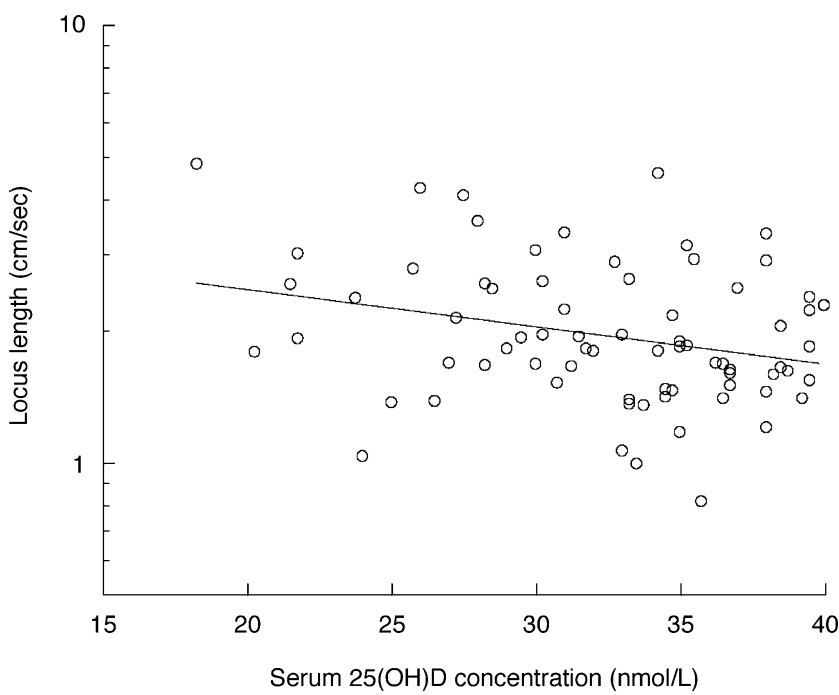

Fig. 1 Scatterplot of serum 25-hydroxyvitamin D (25[OH]D) concentration and locus length of gravity-center sway. Serum 25(OH)D concentration was negatively associated with log-transformed locus length $\left(\beta=-0.0190, \mathrm{R}^{2}=0.075, P=0.0189\right)$
$<40 \mathrm{nmol} / 1$ in ambulatory elderly persons [11]. The association between vitamin D status and the incidence of falls seems significant in vitamin-D-depleted populations. Stein et al. [20] and Flicker et al. [21] demonstrated that low serum 25(OH)D concentrations were associated with falls in ambulant elderly populations (median 25[OH]D concentrations, 27 and $35 \mathrm{nmol} / \mathrm{l}$, respectively). However, one prospective study did not show low serum vitamin $\mathrm{D}$ to predict new disability or loss of muscle strength in older disabled women (mean 25[OH]D, $53 \mathrm{nmol} / \mathrm{l}$ ) [22]. Accordingly, the lack of association between vitamin $\mathrm{D}$ status, balance, and the incidence of falls in the subjects found in this study may be due to relatively high levels of serum 25 $(\mathrm{OH}) \mathrm{D}$ (mean, $60 \mathrm{nmol} / \mathrm{l})$. This study was conducted in late spring to early summer, and the mean serum $25(\mathrm{OH}) \mathrm{D}$ concentration of $60 \mathrm{nmol} / \mathrm{l}$ is as high as that of another Japanese study conducted in the same season [23], suggesting serum $25(\mathrm{OH}) \mathrm{D}$ levels in this study sample were not exceptionally high. Even in winter, active elderly Japanese are known to have high levels of serum 25(OH)D [24].

Dhesi et al. [7] reported that subclinical vitamin D deficiency results in impairment of postural stability, with subjects who had $25(\mathrm{OH}) \mathrm{D}<30 \mathrm{nmol} / 1$ being most affected. Applying the cutoff point of $30 \mathrm{nmol} / 1$ of serum 25(OH)D concentration to this study, subjects with $25(\mathrm{OH}) \mathrm{D}$ $<30 \mathrm{nmol} / \mathrm{l}$ have shorter locus length of gravity-center sway $(P=0.2286)$, weaker grip strength $(P=0.1840)$, and higher incidence of falls $(\mathrm{RR}=1.85,95 \% \mathrm{CI}: 0.83-4.13)$ than those with $25 \mathrm{OHD} \geq 30 \mathrm{nmol} / \mathrm{l}$ (data not shown in "Results" section). Moreover, a negative linear relationship was found between the serum $25(\mathrm{OH}) \mathrm{D}$ concentration and locus length of the gravity-center sway only in the vitaminD-insufficient subgroup $(25[\mathrm{OH}] \mathrm{D}<40 \mathrm{nmol} / \mathrm{l})$. These findings also support the hypothesis that the lack of overall association between serum 25(OH)D concentration and postural sway in this study is considered to be the result of relatively good vitamin $\mathrm{D}$ status.

This study can be compared with the Swedish cohort study [the Osteoporosis Prospective Risk Assessment (OPRA) study] of 986 elderly ambulatory women 75 years of age [12]. The mean serum 25(OH)D concentration of the subjects in the OPRA study was relatively high at, $95 \mathrm{nmol} / 1$, and the serum $25(\mathrm{OH}) \mathrm{D}$ concentration $<75 \mathrm{nmol} / \mathrm{l}$ was associated with inferior muscle strength and postural 
Table 3 Relative risk of falls according to levels of possible risk factors

\begin{tabular}{|c|c|c|c|}
\hline & Relative risk & $(95 \% \mathrm{CI})$ & Trend $P$ value \\
\hline \multicolumn{4}{|l|}{ Age (years) } \\
\hline$<75$ & 1 (reference) & & 0.2404 \\
\hline$\geq 75,<80$ & 1.23 & $(0.75-2.02)$ & \\
\hline$\geq 80$ & 1.48 & $(0.82-2.64)$ & \\
\hline \multicolumn{4}{|l|}{ Height $(\mathrm{cm})$} \\
\hline Q1 $(<142.3)$ & 0.94 & $(0.55-1.63)$ & 0.3695 \\
\hline Q2 ( $\geq 142.3,<145.8)$ & 0.82 & $(0.46-1.43)$ & \\
\hline Q3 ( $\geq 145.8,<149.8)$ & $0.43^{*}$ & $(0.21-0.88)$ & \\
\hline Q4 ( $\geq 149.8)$ & 1 (reference) & & \\
\hline \multicolumn{4}{|l|}{ Weight (kg) } \\
\hline Q1 $(<43.5)$ & 1.16 & $(0.62-2.18)$ & 0.6089 \\
\hline Q2 ( $\geq 43.5,<48.6)$ & 1.10 & $(0.58-2.07)$ & \\
\hline Q3 ( $\geq 48.6,<54.0)$ & 1.23 & $(0.67-2.29)$ & \\
\hline Q4 $(\geq 54.0)$ & 1 (reference) & & \\
\hline \multicolumn{4}{|c|}{ Body mass index $\left(\mathrm{kg} / \mathrm{m}^{2}\right)$} \\
\hline Q1 $(<20.8)$ & 0.68 & $(0.37-1.27)$ & 0.3381 \\
\hline Q2 $(\geq 20.8,<22.9)$ & 0.96 & $(0.55-1.68)$ & \\
\hline Q3 $(\geq 22.9,<25.2)$ & 0.74 & $(0.40-1.37)$ & \\
\hline Q4 ( $\geq 25.2)$ & 1 (reference) & & \\
\hline \multicolumn{4}{|c|}{ Locus length of the center of gravity $(\mathrm{cm} / \mathrm{s})$} \\
\hline Q1 $(<1.5)$ & 1 (reference) & & 0.1335 \\
\hline Q2 $(\geq 1.5,<1.9)$ & $1.97 *$ & $(1.05-3.71)$ & \\
\hline Q3 $(\geq 1.9,<2.5)$ & 0.75 & $(0.34-1.67)$ & \\
\hline Q4 $(\geq 2.5)$ & $1.95^{*}$ & $(1.04-3.66)$ & \\
\hline \multicolumn{4}{|l|}{ Grip strength (kg) } \\
\hline Q1 $(<17.4)$ & 1.44 & $(0.83-2.52)$ & 0.6016 \\
\hline Q2 $(\geq 17.4,<20.3)$ & 0.78 & $(0.40-1.53)$ & \\
\hline Q3 ( $\geq 20.3,<22.9)$ & 0.91 & $(0.48-1.72)$ & \\
\hline Q4 ( $\geq 22.9)$ & 1 (reference) & & \\
\hline \multicolumn{4}{|c|}{ Serum 25-hydroxyvitamin D (nmol/l) } \\
\hline Q1 $(<47.7)$ & 1.12 & $(0.63-2.00)$ & 0.9156 \\
\hline Q2 $(\geq 47.7,<59.4)$ & 0.78 & $(0.41-1.49)$ & \\
\hline Q3 ( $\geq 59.4,<71.1)$ & 0.91 & $(0.50-1.67)$ & \\
\hline Q4 ( $\geq 71.1)$ & 1 (reference) & & \\
\hline \multicolumn{4}{|c|}{ Serum 1,25 -dihydroxyvitamin D (pmol/1) } \\
\hline Q1 $(<112.8)$ & 0.92 & $(0.50-1.69)$ & 0.7894 \\
\hline Q2 ( $\geq 112.8,<134.4)$ & 1.04 & $(0.59-1.84)$ & \\
\hline Q3 ( $\geq 134.4,<165.6)$ & 0.72 & $(0.37-1.38)$ & \\
\hline Q4 ( $\geq 165.6)$ & 1 (reference) & & \\
\hline \multicolumn{4}{|c|}{ Serum intact parathyroid hormone (pmol/l) } \\
\hline Q1 $(<2.44)$ & 1 (reference) & & 0.6126 \\
\hline Q2 $(\geq 2.44,<3.29)$ & 0.64 & $(0.33-1.24)$ & \\
\hline Q3 $(\geq 3.29,<4.24)$ & 1.34 & $(0.77-2.34)$ & \\
\hline Q4 ( $\geq 4.24)$ & 0.87 & $(0.48-1.58)$ & \\
\hline \multicolumn{4}{|l|}{ Serum albumin $(\mathrm{g} / \mathrm{dl})$} \\
\hline Q1 $(<4.0)$ & 0.83 & $(0.43-1.60)$ & 0.3089 \\
\hline Q2 $(\geq 4.0,<4.2)$ & 0.65 & $(0.36-1.15)$ & \\
\hline Q3 $(\geq 4.2,<4.3)$ & 1.11 & $(0.62-1.97)$ & \\
\hline $\mathrm{Q} 4(\geq 4.3)$ & 1 (reference) & & \\
\hline \multicolumn{4}{|l|}{ Do housework } \\
\hline Yes & 1 (reference) & & - \\
\hline No & 0.86 & $(0.41-1.79)$ & \\
\hline \multicolumn{4}{|l|}{ Engage in light exercise } \\
\hline Yes & 1 (reference) & & - \\
\hline No & 1.33 & $(0.82-2.16)$ & \\
\hline
\end{tabular}


Table 3 (continued)

Relative risk

$(95 \% \mathrm{CI})$

Trend $P$ value

Engage in moderate activity

$\begin{array}{ll}\text { Yes } & 1 \text { (reference) } \\ \text { No } & 1.04\end{array}$

1 (reference)

$(0.67-1.60)$

A level that is hypothesized to have the lowest risk of falls is set as a reference group for each variable.

Q1 first quartile, $Q 2$ second quartile, $Q 3$ third quartile, $Q 4$ fourth quartile

$* \mathrm{P}<0.05$

stability. The mean serum 25(OH)D concentration of subjects in the OPRA study is higher than in this study $(60 \mathrm{nmol} / \mathrm{l})$. It should be noted that considerable interassay and interlaboratory variations for the $25(\mathrm{OH}) \mathrm{D}$ determination potentially exist [25]. The interassay difference is negligible because both the present study as well as the OPRA study used the same $25(\mathrm{OH}) \mathrm{D}$ assay (the Nichols Advantage $^{\mathrm{R}}$ chemiluminescent assay). However, there is possibly an interlaboratory variation leading to an overestimation of the difference $(35 \mathrm{nmol} / \mathrm{l})$ in serum $25(\mathrm{OH}) \mathrm{D}$ concentration between the two studies. In any case, the mean serum $25(\mathrm{OH}) \mathrm{D}$ concentrations of subjects in both the OPRA study and the present study are relatively high, and yet significant associations between serum 25(OH)D concentrations and muscle balance and strength were found only in the OPRA study. Though the discrepancy between the results of this study and the OPRA study cannot be fully explained, it is hypothesized that the disparity between the two studies is due to the different ethnicities of study populations, given that the threshold value of serum 25 $(\mathrm{OH}) \mathrm{D}$ concentration for vitamin D insufficiency in elderly Japanese is lower than in elderly Caucasians.

The 1-year fall incidence of $12 \%$ in this study appeared to be lower than that in many previous studies, which reported around $30-40 \%$ in community-dwelling elderly in Europe and North America [26]. One reason explaining this discrepancy may be that the subjects were volunteers who were physically healthier than the general population, which includes the frail elderly. Another explanation may be ethnic differences. The 1-year incidence of falls previously reported in the community-dwelling elderly in Japan ranged from 10-20\% [27], which is generally lower than the incidence in Europe or North America. The lower incidence of falls in elderly Japanese may be due to relatively good vitamin D status, as discussed earlier, as well as other important risk factors for falls, including genetic issues.

This study has some limitations. First, there may be a misclassification bias in recalling falls, which could lead an association between vitamin D status and fall occurrence toward the null. Second, the participation rate of this study was not high, especially regarding women in their 80 s and older. This may have led to selection bias based on the assumption that very elderly participants were probably healthier than nonparticipants. Finally, participants were healthy female persons living in a community whereas frail and/or disabled elderly persons were not included. Therefore, generalization of the results should be made with caution.

In conclusion, the present study failed to find an association between vitamin D status and postural sway, muscle strength, or the 1-year incidence of falls in elderly community-dwelling Japanese women. This may be due to relatively high serum $25(\mathrm{OH}) \mathrm{D}$ levels. Therefore, vitamin D status may not be an important factor for the prevention of falls in ambulant elderly Japanese women. However, a significant association between vitamin $\mathrm{D}$ status and postural sway was found in the vitamin-D-insufficient subgroup, suggesting supplementation of vitamin D should be considered for those with vitamin D insufficiency.

Acknowledgements We wish to thank the staff of Muramatsu Health Center for their help in data collection. This study was supported in part by a grant for scientific research relating to health promotion focusing on physical exercise from the Nakatomi Foundation (2003), a grant from the Japan Rheumatism Foundation (2003), and the Japan Osteoporosis Society Encouragement Award (2004).

\section{References}

1. Pfeifer M, Begerow B, Minne HW (2002) Vitamin D and muscle function. Osteoporos Int 13:187-194

2. Janssen HCJP, Samson MM, Verhaar HJJ (2002) Vitamin D deficiency, muscle function, and falls in elderly people. Am J Clin Nutr 75:611-615

3. Simpson RU, Thomas GA, Arnold AJ (1985) Identification of 1,25-dihydroxyvitamin D3 receptors and activities in muscle. J Biol Chem 260:8882-8891

4. Bischoff HA, Borchers M, Gudat F, Duermueller U, Theiler R, Stahelin HB, Dick W (2001) In situ detection of 1,25-dihydroxyvitamin D3 receptor in human skeletal muscle tissue. Histochem J 33:19-24

5. Bischoff HA, Stahelin HB, Urscheler N, Ehrsam R, Vonthein R, Perrig-Chiello P, Tyndall A, Theiler R (1999) Muscle strength in the elderly: its relation to vitamin D metabolites. Arch Phys Med Rehabil 80:54-58

6. Mowe M, Haug E, Bohmer T (1999) Low serum calcidiol concentration in older adults with reduced muscular function. J Am Geriatr Soc 47:220-226

7. Dhesi JK, Bearne LM, Moniz C, Hurley MV, Jackson SH, Swift CG, Allain TJ (2002) Neuromuscular and psychomotor function in elderly subjects who fall and the relationship with vitamin D status. J Bone Miner Res 17:891-897 
8. Pfeifer M, Begerow B, Minne HW, Abrams C, Nachtigall D, Hansen C (2000) Effects of a short-term vitamin D and calcium supplementation on body sway and secondary hyperparathyroidism in elderly women. J Bone Miner Res 15:1113-1118

9. Bischoff-Ferrari HA, Dawson-Hughes B, Willett WC, Staehelin HB, Bazemore MG, Zee RY, Wong JB (2004) Effect of Vitamin D on falls: a meta-analysis. JAMA 291:1999-2006

10. Bischoff-Ferrari HA, Orav EJ, Dawson-Hughes B (2006) Effect of cholecalciferol plus calcium on falling in ambulatory older men and women: a 3-year randomized controlled trial. Arch Intern Med 166:424-430

11. Bischoff-Ferrari HA, Dietrich T, Orav EJ, Hu FB, Zhang Y, Karlson EW, Dawson-Hughes B (2004) Higher 25-hydroxyvitamin D concentrations are associated with better lower-extremity function in both active and inactive persons aged $\geq 60 \mathrm{y}$. Am J Clin Nutr 80:752-758

12. Gerdhem P, Ringsberg KA, Obrant KJ, Akesson K (2005) Association between 25-hydroxy vitamin D levels, physical activity, muscle strength and fractures in the prospective population-based OPRA Study of Elderly Women. Osteoporos Int $16: 1425-1431$

13. Aoyagi K, Ross PD, Davis JW, Wasnich RD, Hayashi T, Takemoto T (1998) Falls among community-dwelling elderly in Japan. J Bone Miner Res 13:1468-1474

14. Morita Y, Endo N, Iga T, Tokunaga K, Ohkawa Y (2002) The incidence of cervical and trochanteric fractures of the proximal femur in 1999 in Niigata Prefecture, Japan. J Bone Miner Metab 20:311-318

15. Nakamura K, Saito T, Nishiwaki T, Ueno K, Nashimoto M, Okuda Y, Tsuchiya Y, Oshiki R, Muto K, Yamamoto M (2006) Correlations between bone mineral density and demographic, lifestyle and biochemical variables in community-dwelling Japanese women 69 years of age and over. Osteoporos Int 17:1202-1207

16. Black FO, Wall C, Rockette HE et al (1982) Normal subject postural sway during the Romberg test. Am J Otolaryngol 3:309-318

17. Maeda A, Nakamura K, Otomo A, Higuchi S, Motohashi Y (1998) Body support effect of on standing balance in the visually impaired elderly. Arch Phys Med Rehabil 79:994-997
18. Schwartz AV, Capezuti E, Grisso JA (2001) Falls as risk factors for fractures. In: Marcus R, Feldman D, Kelsey J (eds) (2001) Osteoporosis, Second edition, vol 1. Academic Press, San Diego, pp 795-807

19. Nakamura K, Nashimoto M, Tsuchiya Y, Saito T, Nishiwaki T, Ueno K, Okuda Y, Oshiki R, Yamamoto $M$ (in press) The threshold value of serum 25-hydroxyvitamin $\mathrm{D}$ concentration in relation to elevated serum parathyroid hormone concentrations in elderly Japanese women. J Bone Miner Metab

20. Stein MS, Wark JD, Scherer SC, Walton SL, Chick P, Di Carlantonio M, Zajac JD, Flicker L (1999) Falls relate to vitamin $\mathrm{D}$ and parathyroid hormone in an Australian nursing home and hostel. J Am Geriatr Soc 47:1195-1201

21. Flicker L, Mead K, MacInnis RJ, Nowson C, Scherer S, Stein MS, Thomasx J, Hopper JL, Wark JD (2003) Serum vitamin D and falls in older women in residential care in Australia. J Am Geriatr Soc 51:1533-1538

22. Verreault R, Semba RD, Volpato S, Ferrucci L, Fried LP, Guralnik JM (2002) Low serum vitamin D does not predict new disability or loss of muscle strength in older women. J Am Geriatr Soc 50:912-917

23. Nakamura K, Nashimoto M, Endoh K, Yamamoto M (2000) Vitamin D nutritional status of women living on a solitary island in Japan: a population-based study. Environ Health Prev Med $5: 49-52$

24. Nakamura K, Nashimoto M, Hori Y, Yamamoto M (2000) Serum 25-hydroxyvitamin D concentrations and related dietary factors in peri- and postmenopausal Japanese women. Am J Clin Nutr 71:1161-1165

25. Binkley N, Krueger D, Cowgill CS, Plum L, Lake E, Hansen KE, DeLuca HF, Drezner MK (2004) Assay Variation Confounds the Diagnosis of Hypovitaminosis D: A Call for Standardization. J Clin Endocrinol Metab 89:3152-3157

26. Masud T, Morris RO (2001) Epidemiology of falls. Age Ageing 30(Suppl 4):3-7

27. Harada A, Matsui Y (2002) Falls and fractures in elderly people. Seikei-saigaigeka (Orthop Surg Traumatol) 45:715-722 (in Japanese) 